\title{
Commentary The pursuit of a high central venous oxygen saturation in sepsis: growing concerns
}

\author{
Rinaldo Bellomo, Michael C Reade and Stephen J Warrillow
}

Department of Intensive Care, Austin Hospital, Studley Rd, Heidelberg, Victoria 3084, Australia

Corresponding author: Rinaldo Bellomo, Rinaldo.bellomo@austin.org.au

Published: 7 April 2008

Critical Care 2008, 12:130 (doi:10.1186/cc6841)

This article is online at http://ccforum.com/content/12/2/130

(c) 2008 BioMed Central Ltd

See related research by van Beest et al., http://ccforum.com/content/12/2/R33

\begin{abstract}
In this issue of Critical Care, Dutch investigators report that, in a cohort of patients with sepsis/septic shock admitted to three different intensive care units (ICUs), low central venous oxygen saturation $\left(\mathrm{ScvO}_{2}\right)$ was uncommon at the time of ICU admission, and hospital mortality was $<30 \%$. Their findings, taken together with those of recent reports from Australia and New Zealand (ANZ), raise serious concerns about the utility of early goal directed therapy (EGDT) outside the context of the original trial. Despite inclusion of EGDT into the Surviving Sepsis Guidelines, in response to growing uncertainty, ANZ and US investigators will soon begin randomization of patients into two large multicentre trials comparing EGDT to standard therapy. Until such studies are completed, basing international treatment guidelines on a single centre study performed in what may turn out to be a highly atypical environment would seem premature.
\end{abstract}

Many physicians believe that global hypoxia secondary to inadequate oxygen delivery $\left(\mathrm{DO}_{2}\right)$ is responsible for organ failure during severe sepsis. Others believe that sepsis is an inflammatory condition in which abnormalities of $\mathrm{DO}_{2}$ are uncommon. The relative importance of each of these hypotheses, and indeed whether other unknown factors play a role, is simply not known. The issue of $\mathrm{DO}_{2}$ and oxygen consumption in sepsis is highlighted in the paper by van Beest and colleagues [1] in this edition of Critical Care. These authors have focused on central venous oxygen saturation $\left(\mathrm{ScvO}_{2}\right)$ as a marker of systemic oxygenation. They have done this partly in response to the following fashionable, but yet untested, concepts: first, $\mathrm{ScvO}_{2}$ is a reliable marker of global tissue hypoxia; second, increasing $\mathrm{ScvO}_{2}$ by early goal directed therapy (EGDT) [2] improves outcome; and third, we should follow the Surviving Sepsis Campaign Guidelines [3] by pursuing a $\mathrm{SvcO}_{2}>70 \%$ in septic patients. Their findings suggest that the passive acceptance of the above conceptual triad may be unwise. Only 6\% of septic patients in their study had a $\mathrm{SvcO}_{2}$ below physiological normality. The mean $\mathrm{ScvO}_{2}$ was $74 \%$, compared to $48.9 \%$ in the EGDT study. Certainly, the Dutch patients were different to those in the EGDT study in several important respects: only half were admitted from the emergency department, and many must have received intravenous fluid prior to their intensive care unit (ICU) admission. Despite comparable APACHE II scores, mortality of septic patients in the Dutch study (26\%) was much less than in the EGDT standard care arm (46.5\%), and less even than in the intervention arm (30\%) of that trial. Septic patients presenting to a Dutch ICU would, therefore, be expected to derive no benefit from EGDT-style attempts to increase their (already normal) ScvO2.

These observations raise provocative questions about the utility of applying the principles of EGDT outside the single US urban hospital in which the trial was performed. Perhaps, though, it is the Dutch data that are unique and unrepresentative? This seems unlikely, as another study conducted in Australia [4] reported essentially identical mortality (29\%) to that in the Netherlands, again below that reported by Rivers and colleagues with EGDT, and almost half that seen in the control group of that study. Perhaps the similarity of these two studies is just coincidence. However, a further recent study from Australia and New Zealand (ANZ) reported hospital mortality from severe sepsis/septic shock was close to $27 \%$ in 7,649 patients admitted to ICU from the emergency department [5]. Even if these three independent and remarkably consistent observations were dismissed as a matter of chance, the recently completed ANZ Intensive Care Society (ANZICS) Clinical Trials Group prospective study of septic patients in more than 30 hospitals (soon to be presented at the 2008 Brussels meeting) also found a $27 \%$

ANZ = Australia and New Zealand; ANZICS = ANZ Intensive Care Society; $\mathrm{DO}_{2}=$ oxygen delivery; EGDT = early goal directed therapy; ICU $=$ intensive care unit; $\mathrm{ScvO}_{2}=$ central venous oxygen saturation. 
mortality rate. There is an elephant in the room: the baseline mortality of severe sepsis/septic shock with standard care in the Netherlands and ANZ is substantially less than in the EGDT study. This raises serious concerns. Were the EGDT study findings the result of re-alignment of limited quality care back to a level considered acceptable elsewhere? Do they apply to countries with 'closed' ICU systems [6] such as the Netherlands and ANZ? Are the recommendations of the Surviving Sepsis Campaign premature? In response to such uncertainty, ANZICS has for now chosen not to endorse these guidelines [7]. Indeed, once the virus of scepticism takes hold one can see all sorts of uncertainties in the biological construct and rationale underpinning EGDT. Is there an oxygen debt in sepsis? Many would argue not [8-10]. Is $\mathrm{ScvO}_{2}$ a robust marker of such global tissue hypoxia? How would we know? What test would confirm or refute whether such global hypoxia exists? Is high lactate a marker of tissue hypoxia and 'anaerobic metabolism'? The answer to this last question is an easy, emphatic 'absolutely not'! [11-15]. Should we pursue EGDT in septic patients? The answer is 'not yet'. We need to assess the value of EGDT in multicenter randomized controlled trials. The ANIZCS Clinical Trials Group will soon begin an Australian National Health and Medical Research Council-funded randomised controlled trial, the Australasian Resuscitation In Sepsis Evaluation (ARISE). This trial will randomize 1,500 patients and compare EGDT with standard care. US investigators will soon begin ProCESS (Protocolized Care Early Severe Sepsis), a similar NIH-funded multicentre trial to address the same issue. Until the results of such trials are available, the intensivist, emergency physician and hospital administrator would do well to remain cautious about the routine application of EGDT to their septic patients.

\section{Competing interests}

The authors declare that they have no competing interests.

\section{References}

1. van Beest PA, Hofstra JJ, Schultz MJ, Boerma EC, Spronk PE, Kuiper MA: The incidence of low venous oxygen saturation on admission to the intensive care unit: a multi-centre observational study in The Netherlands. Crit Care 2008, 12:R33.

2. Rivers E, Nguyen B, Havstad S, Ressler J, Muzzin A, Knoblich B, Tomlanovich M: Early goal directed therapy in the treatment of severe sepsis and septic shock. N Engl J Med 2001, 345: 1368-1377.

3. Dellinger RP, Levy MM, Carlet JM, Bion J, Parker MM, Jaeschke R, Reinhart K, Angus DC, Brun-Buisson C, Beale R, Calandra T, Dhainaut JF, Gerlach H, Harvey M, Marini JJ, Marshall J, Ranieri M, Ramsay G, Sevransky J, Thompson BT, Townsend S, Vender JS, Zimmerman JL, Vincent JL: Surviving sepsis campaign: international guidelines for management of severe sepsis and septic shock: 2008. Intensive Care Med 2008, 34:17-60.

4. Ho BCH, Bellomo R, McGain F, Jones D, Naka T, Wan L, Bratiberg G: The incidence and outcome of septic shock patients in the absence of early goal directed therapy. Crit Care 2006, 10:R80.

5. The ARISE Investigators and the ANZICS Adult Patient Database Management Committee: The outcome of patients with sepsis and septic shock presenting to emergency departments in Australia and New Zealand. Crit Care Resusc 2007, 9:8-18.

6. Bellomo R, Stow P, Hart GK: Why is there such a difference in outcome between Australia intensive care units and others?
Curr Opin Anaesthesiol 2007, 20:100-105.

7. Hicks P, Coper DJ, The ANZICS Board and Clinical Trials Group Executive Committee: The surviving sepsis campaign: international guidelines for management of severe sepsis and septic shock: 2008. Crit Care Resusc 2008, 10:8.

8. Ronco JJ, Fenwick JC, Tweeddale MG, Wiggs BR, Phang PT, Cooper DJ, Cunningham KF, Russell JA, Walley KR: Identification of the critical oxygen delivery for anaerobic metabolism in critically ill septic and nonseptic humans. JAMA 1993, 270: 1724-1730.

9. Ronco JJ, Fenwick JC, Wiggs BR, Phang PT, Russell JA, Tweeddale MG: Oxygen consumption is independent of increases in oxygen delivery by dobutamine in septic patients who have normal or increased plasma lactate. Am Rev Respir Dis 1993, 147:25-31.

10. Ronco JJ, Fenwick JC, Tweeddale MG: Does increasing oxygen delivery improve outcome in the critically ill? No. Crit Care Clin 1996, 12:645-659.

11. Schurr A, Payne RS: Lactate, not pyruvate, is neuronal aerobic glycolysis end product: an in vitro electrophysiological study. Neuroscience 2007, 147:613-619.

12. Brooks GA: Lactate: link between glycolytic and oxidative metabolism. Sports Med 2007, 37:341-343.

13. Levy B: Lactate and shock state: the metabolic view. Curr Opin Crit Care 2006, 12:315-321.

14. Gladden LB: Lactate metabolism: a new paradigm for the third millennium. J Physio/ 2004, 558:5-30.

15. Levy B, Gibot S, Franck P, Cravoisy A, Bollaert PE: Relation between muscle $\mathrm{Na}+\mathrm{K}+$ ATPase activity and raised lactate concentrations in septic shock: a prospective study. Lancet 2005, 365:871-875. 